\title{
Vortex-Induced Vibration Analysis of Deep-Sea Riser
}

\author{
Seongjong Park ${ }^{*}$ and Bongjae Kim* \\ *Central Research Institute, Samsung Heavy Industry, Seongnam, Korea \\ 심해 라이저의 와류유기 진동해석 \\ 박성종* 김봉재 \\ "삼성중공업(주) 중앙연구소
}

KEY WORDS: Steel catenary riser 카티너리 라이저, Top tensioned riser 상부장력 라이저, Vortex-induced vibration 와류유기 진동, Fatigue damage 피로 손상, Mode superposition 모드 중첩

\begin{abstract}
A numerical model based on the mode superposition method is used to study the vortex-induced vibration response characteristics of a deep-sea riser such as steel catenary riser (SCR). A steel catenary riser can be modeled using a flexible cable with simple supports at both ends. The natural frequency, mode shape and mode curvature of the riser are calculated and the vortex-induced vibration response of the riser is obtained using the equilibrium of the input and output power. The mode superposition method is applied to the vibrational stresses for each mode to calculate the overall riser fatigue life.
\end{abstract}

\section{1. 서 론}

심해역 해양자원의 개발 추세와 함께 라이저의 적용 수심은 점 점 깊어지고 있다. 심해역에 설치되는 라이저는 높은 압력 등 열악 한 환경에 노출되기 쉽다. 카티너리 라이저(Steel Catenary Riser, $\mathrm{SCR}$ )는 상부장력 라이저(Top Tensioned Riser, TTR)에 비하여 더욱 큰 선박의 움직임을 허용하며, 플렉서블 라이저(Flexible Riser)에 비하여 열악한 환경에 더욱 잘 견딜 수 있다. 따라서 카티너리 라이 저는 심해 자원개발에 가장 넓게 적용되고 있다. 카티너리 라이저 는 수명기간 중 해류와 파랑 등의 외부 하중에 지속적으로 노출되 며, 구조적인 안정성을 확보하기 위하여 이와 같은 외부환경에 잘 견딜 수 있도록 설계되어야 한다. 따라서 라이저의 피로수명을 예 측하는 것이 설계의 핵심 중 하나이다.

라이저가 설치된 해역에 일정한 속도 이상의 해류가 흐르는 경 우, 급격한 구배 변화로 인하여 라이저 뒷면에는 규칙적인 패턴의 와류 흘림(Vortex Shedding) 현상이 발생하게 된다. 와류 흘림은 라이저에 주기적으로 하중을 발생시키며, 라이저의 움직임과 상호 작용에 의하여 와류유기 진동(Vortex-Induced Vibration, VIV)을 발 생시킨다. 특히, 와류 흘림 주파수가 라이저의 고유진동수(Natural Frequency)와 가까워지면 라이저는 와류 흘림과 동조화되어 대변
위 진동이 발생하게 된다. 이를 Lock-in 현상이라고 하며, 이 때 라이저는 큰 구조 응력에 의하여 피로손상이 발생한다(Park et al., 2004).

이와 같은 와류유기 진동에 의한 라이저의 피로수명을 예측 하기 위하여 많은 연구가 진행되었다. $\operatorname{Kim}(2013)$ 과 Youn(2016) 은 파워입력범위와 분포방법에 따른 상부장력 라이저의 와류유 기 진동 특성을 연구하였으며, Gao 등(Gao et al., 2011)은 카티 너리 라이저의 와류유기 진동에 의한 피로 수명을 예측하였다. Vikestad 등(Vikestad et al., 2000)은 Venugopal(1996)이 제시한 유체 감쇠 모델을 Gopalkrishnan(1993)과 Vikestad(1998)의 실험 과 비교하였다.

본 연구에서는 모드중첩법에 기반한 수치모델을 제시하여 카 티너리 라이저의 와류유기 진동 수치해석기법을 정리한다. 카 티너리 라이저는 양단이 단순지지된 유연한 케이블로 모델링되 며, 입력과 출력 파워의 평형을 이용하여 진동 응답 및 피로수 명을 계산한다.

\section{2. 수치 이론}

심해 라이저는 길이가 지름에 비하여 매우 크며 $(L / D>200)$, 이

Received 27 June 2017, revised 18 September 2017, accepted 19 October 2017

Corresponding author Seongjong Park: +82-31-5171-7595, sj07.park@samsung.com

It is noted that this paper is revised edition based on proceedings of KAOST 2010 in Jeju.

(c) 2017, The Korean Society of Ocean Engineers

This is an open access article distributed under the terms of the creative commons attribution non-commercial license (http://creativecommons.org/licenses/by-nc/3.0) which permits unrestricted non-commercial use, distribution, and reproduction in any medium, provided the original work is properly cited. 
경우 라이저는 유연한 케이블로 간주할 수 있다(DNV, 2006). 외 력이 작용하는 케이블의 지배방정식은 다음과 같다(Gao et al., 2011).

$$
m(s) \frac{\partial^{2} y(s, t)}{\partial t^{2}}+R(s) \frac{\partial y(s, t)}{\partial t}-T(s) \frac{\partial^{2} y(s, t)}{\partial s^{2}}=P(s, t)
$$

여기서, $m(S)$ 는 접수에 의한 부가질량을 포함한 단위 길이당 질량, $R(s)$ 는 단위 길이당 감쇠, $T(s)$ 는 유효장력, $P(s, t)$ 는 라 이저에 작용하는 외력이며, $s$ 와 $t$ 는 각각 위치좌표와 시간을 나 타낸다. 외력은 와류흘림에 의해 주기적으로 작용하므로 $P(s, t)$ 는 다음과 같이 나타낼 수 있다.

$$
P(s, t)=\frac{1}{2} \rho_{f} D V^{2}(s) C_{L}\left(s ; \omega_{r}\right) \sin \left(\omega_{r} t\right)
$$

여기서, $\rho_{f}$ 는 유체 밀도, $D$ 는 라이저 지름, $V(s)$ 는 해류 속도, 은 $C_{L}\left(s ; \omega_{r}\right) r$ 번째 고유모드에 대한 양력계수이다.

$Y_{r}(s)$ 와 $q_{r}(s)$ 를 각각 $r$ 번째 고유모드와 모드좌표계라고 정 의하면, 라이저의 변위 응답을 다음과 같이 각 모달 변위의 중 첩으로 나타낼 수 있다.

$$
y(s, t)=\sum_{r} Y_{r}(s) q_{r}(t)
$$

식 (3)을 식 (1)에 넣고 정리하면, 다음과 같은 모드좌표계에 서의 운동방정식을 얻을 수 있다.

$$
M_{r} \frac{d^{2} q_{r}(t)}{d t^{2}}+R_{r} \frac{d q_{r}(t)}{d t}+K_{r} q_{r}(t)=P_{r}(t)
$$

여기서, $M_{r}, R_{r}, K_{r}, P_{r}(t)$ 는 각각 $r$ 번째 모달 질량, 모달 감쇠, 모달 강성 및 모달 힘이며, 식 (5)에서 식 (8)과 같다.

$$
\begin{aligned}
& M_{r}=\int_{0}^{L} Y_{r}^{2}(s) m(s) d s \\
& R_{r}=\int_{0}^{L} Y_{r}^{2}(s) R(s) d s \\
& K_{r}=-\int_{0}^{L} Y_{r}^{\prime \prime}(s) Y_{r}(s) T d s \\
& P_{r}(t)=\int_{0}^{L} Y_{r}(s) P(s, t) d s
\end{aligned}
$$

여기서, double prime(")은 2계 미분을 나타낸다.

입력 파워는 외력과 속도의 곱으로 나타낼 수 있으며, $r$ 번째 모드의 입력 파워는 다음과 같다.

$$
\Pi_{r}^{i n}=\int_{0}^{L} \frac{1}{2} \rho_{f} D V^{2}(s) C_{L}\left(s ; \omega_{r}\right) A_{r} \omega_{r} \sin ^{2}\left(\omega_{r} t\right) \times\left|Y_{r}(s)\right| \Phi(s) d s
$$

여기서, $A_{r}$ 은 $r$ 번째 모드변위의 진폭(Mode Displacement Amplitude) 이며, $\Phi(s)$ 는 외력의 가진 범위와 기여도를 나타내는 함수이다 (Kim, 2013). 본 연구에서는 파워입력이 중복되는 경우, 중복되는 모드의 파워 크기에 비례하여 기여도를 결정하였다.

또한, 출력 파워는 감쇠력과 속도의 곱으로 나타낼 수 있으며, $r$ 번째 모드의 출력 파워는 다음과 같다.

$$
\Pi_{r}^{\text {out }}=\int_{0}^{L} Y_{r}^{2}(s) R(s) A_{r}^{2} \omega_{r}^{2} \sin ^{2}\left(\omega_{r} t\right) d s
$$

$r$ 번째 모드의 한 주기 동안의 시간 평균 입력파워 및 출력파 워는 각각 식 (11) 및 식 (12)와 같다.

$$
\begin{aligned}
& \Pi_{r}^{\text {in }}=\int_{0}^{L} \frac{1}{4} \rho_{f} D V^{2}(s) C_{L}\left(s ; \omega_{r}\right) A_{r} \omega_{r}\left|Y_{r}(s)\right| \Phi(s) d s \\
& \left\langle\Pi_{r}^{\text {out }}\right\rangle=\int_{0}^{L} \frac{1}{2} Y_{r}^{2}(s) R(s) A_{r}^{2} \omega_{r}^{2} d s
\end{aligned}
$$

각각의 모드에 대하여 입력 파워와 출력 파워는 평형을 이루 므로, 다음을 얻을 수 있다.

$$
\frac{A_{r}}{D}=\frac{\int_{0}^{L} \frac{1}{2} \rho_{f} V^{2}(s) C_{L}\left(s ; \omega_{r}\right)\left|Y_{r}(s)\right| \Phi(s) d s}{\int_{0}^{L} Y_{r}^{2}(s) R(s) \omega_{r} d s}
$$

$A_{r} / D$ 의 초기값을 가정하면 감쇠 $R(s)$ 와 양력 계수 $C_{L}\left(s ; \omega_{r}\right)$ 을 구할 수 있으며, 이를 이용하여 다시 $A_{r} / D$ 를 구할 수 있다. 이를 반복적으로 계산하여 연속적인 $A_{r} / D$ 의 값의 차이가 일정 한 값 이하이면 수렴한 것으로 판단한다.

단위 길이당 감쇠 $R(s)$ 는 구조감쇠 $R_{s}$ 와 유체동역학적 감쇠 $R_{h}(\mathrm{~s})$ 로 구성되며, 본 연구에서 구조감쇠는 0.003 으로 가정한 다. 그리고 유체동역학적 감쇠는 감소속도(Reduced Velocity)를 기준으로 두 개의 다른 모델로 나타난다(Vikestad et al., 2000). 저속 (Low Reduced Velocity) 범위인 파워 입력 구간에서 $R_{h}(s)$ 는 식 (14)와 같고, 고속(High Reduced Velocity) 범위인 파워 출 력 구간에서 $R_{h}(s)$ 는 식 (15)와 같다.

$$
\begin{aligned}
& R_{h, \text { low }}=\frac{\omega \pi \rho_{f} D^{2}}{2}\left[2 \sqrt{\frac{2}{R e}+C_{s w}\left(\frac{A_{r}}{D}\right)^{2}}\right]+C_{r l} \rho_{f} D V(s) \\
& R_{h, h i g h}=\frac{C_{r h} \rho_{f} V^{2}(s)}{\omega}
\end{aligned}
$$

여기서, $C_{s w}, C_{r l}, C_{r h}$ 는 각각 정수(Still Water), 저속 및 고속에서 의 경험계수이며, 각각 $0.20,0.18,0.20$ 이 적용되었다. 또한, $\mathrm{Re}$ 는 레이놀즈 수(Reynolds Number)이며, 다음과 같이 나타낸다.

$$
R e=\frac{\omega D^{2}}{\nu}
$$




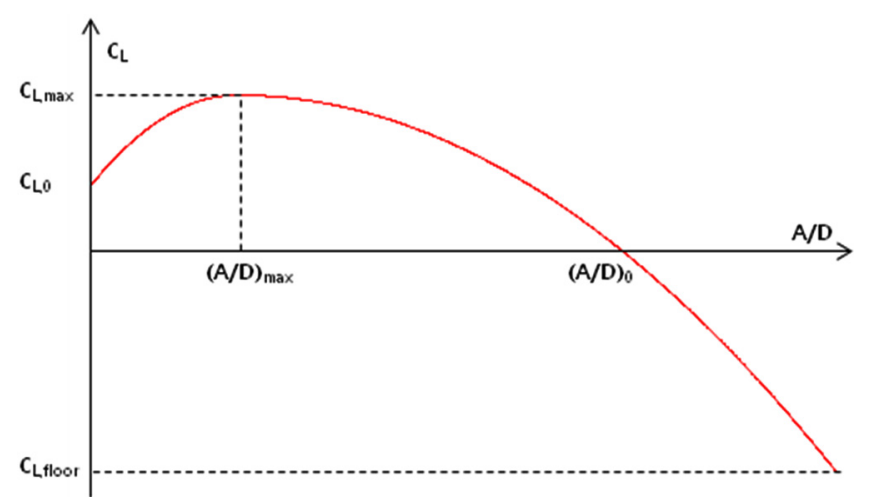

Fig. 1 Lift coefficient model

Table 1 Lift coefficient(Vandiver and Li, 2015)

\begin{tabular}{cc}
\hline \hline Item & Value \\
\hline$A / D_{\max }$ & 0.30 \\
$A / D_{0}$ & 1.10 \\
$C_{L, \max }$ & 0.70 \\
$C_{L, 0}$ & 0.30 \\
$C_{L, \text { floor }}$ & -1.00 \\
\hline
\end{tabular}

여기서, $v$ 는 유체점성(Fluid Viscosity)이다.

라이저의 양력 계수 $C_{L}$ 은 무차원 응답 진폭 $A / D$ 의 함수로 표현할 수 있다(Vandiver and $\mathrm{Li}, 2005) . C_{L}$ 은 Fig. 1과 같이 세 점을 연결하는 두 개의 포물선의 조합으로 구성되며, 양력계수 의 최소값 $C_{L, f l o o r}$ 가 정의된다. 본 연구에서는 Table 1 에 정리된 값을 이용하여 양력계수를 추정하였다.

단순지지(pinned-pineed) 조건에서 식 (4)를 이용하여 식 (17) 및 식 (18)과 같이 라이저의 고유진동수 $\omega_{r}$ 과 고유모드 $Y_{r}(s)$ 를 구할 수 있다.

$$
\begin{aligned}
& \omega_{r}=\frac{r \pi}{\int_{0}^{L} \sqrt{\frac{m}{T(s)} d s}} \\
& Y_{r}(s)=\sin \left[\int_{0}^{s} \sqrt{\frac{m}{T(s)} \omega_{r} d s}\right]
\end{aligned}
$$

RMS 응력(Root Mean-Squared Stress)은 다음과 같다(Vandiver and $\mathrm{Li}, 2005)$.

$$
S_{\mathrm{rms}}(s)=\left\{\sum_{r} \frac{1}{8}\left|\sum_{n} Y_{n}^{\prime \prime}(s) E D_{s} P_{n r} H_{n r}\left(\frac{\omega_{r}}{\omega_{n}}\right)\right|^{2}\right\}^{1 / 2}
$$

여기서, $n$ 과 $r$ 은 고유모드이며, $E$ 는 탄성계수(Young's Modulus), $D_{s}$ 는 강력 지름 (Strength Diameter)이다. 모달 힘 $P_{n r}$ 과 주파수 응답 함수 $H_{n r}$ 은 각각 식 (20) 및 식 (21)과 같다.

$$
P_{n r}=\int_{0}^{L} \operatorname{sgn}\left[Y_{r}(s)\right] Y_{n}(s) P_{r}(s) \Phi(s) d s
$$

$$
H_{n r}\left(\frac{\omega_{r}}{\omega_{n}}\right)=\frac{1}{K_{n}} \frac{1}{\left[1-\left(\frac{\omega_{r}}{\omega_{n}}\right)^{2}+2 i \zeta_{n} \frac{\omega_{r}}{\omega_{n}}\right]}
$$

여기서, $\operatorname{sgn}[()]$ 는 다음과 같은 부호 함수이다.

$$
\begin{aligned}
& \operatorname{sgn}[()]=+1 \text { if }()>0 \\
& \operatorname{sgn}[()]=-1 \text { if }()<0 \\
& \operatorname{sgn}[()]=0 \text { if }()=0
\end{aligned}
$$

또한, 감쇠비 $\zeta_{n}$ 은 구조 감쇠비 $\zeta_{n, s}(=0.003)$ 와 유체동역학적 감 쇠비 $\zeta_{n, h}$ 로 구성되며, 유체동역학적 감쇠비 $\zeta_{n, h}$ 는 다음과 같다.

$$
\zeta_{n, h}=\frac{\int R_{h}(s) Y_{n}^{2}(s) d s}{2 \omega_{n} \int m(s) Y_{n}^{2}(s) d s}
$$

가진 주파수 $\omega_{r}$ 에 대한 와류유기 피로손상은 다음과 같이 나 타낼 수 있다.

$$
E_{r}(s)=\frac{\omega_{r} T}{2 \pi c}\left[\sqrt{2} S_{r, \mathrm{rms}}(s)\right]^{b} \Gamma\left(\frac{b+2}{2}\right)
$$

여기서, $\Gamma($ )는 식 (25)에 의해 정의되는 감마(Gamma)함수이다. 또한 $b$ 와 $c$ 는 식 (26)에 의해 정의되는 S-N(응력-반복횟수) 곡선 의 계수이며, $S_{r, \mathrm{rms}}$ 는 식 (27)과 같다.

$$
\begin{aligned}
& \Gamma(z)=\int_{0}^{\infty} \frac{t^{z-1} d t}{\exp t} \\
& N(S \times S C F)^{b}=c \\
& S_{r, \mathrm{rms}}(s)=\frac{1}{2 \sqrt{2}}\left[\sum_{n} Y_{n}^{\prime \prime}(s) E D_{s} P_{n r} H_{n r}\left(\frac{\omega_{r}}{\omega_{n}}\right)\right]
\end{aligned}
$$

여기서, $S$ 는 응력, $N$ 은 반복의 수이며, $S C F$ 는 Stress Concentration Factor로 1.2 를 적용하였다(GAO et al., 2011).

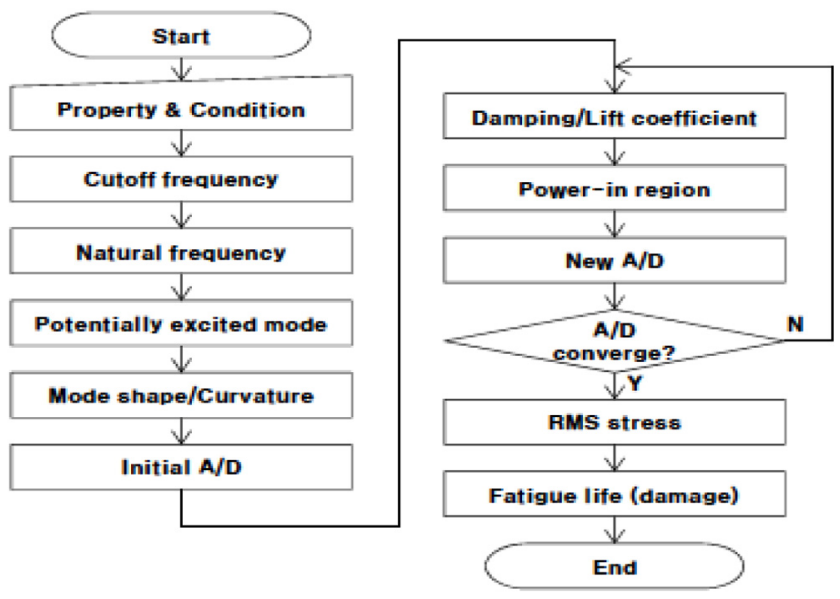

Fig. 2 Road map of riser VIV analysis 
이를 정리하면, 라이저의 와류유기 진동해석 기법에 대한 흐 름도는 Fig. 2와 같다.

\section{3. 수치 해석}

\section{1 검증 모델}

Fig. 3과 같은 카티너리 라이저의 플랫폼 수직 설치각도 (Hang-Off Angle, HOA)가 $\theta$ 인 라이저의 플랫폼 설치점과 해저 면 사이의 거리를 $H$ 라고 가정하면, 카티너리 방정식에 의해 라 이저의 전체 길이 $L$ 은 다음과 같다.

$$
L=H \frac{\cos \theta}{1-\sin \theta}
$$

라이저와 해저면의 교점을 원점, 수면 방향을 $y$ 축, 흐름 방향 을 $x$ 축으로 하는 좌표 평면을 가정하면, 카티너리 라이저는 다 음의 식으로 나타낼 수 있다.

$$
y=\frac{L^{2}-H^{2}}{2 H}\left[\cosh \left(\frac{2 H}{L^{2}-H^{2}} x\right)-1\right]
$$

라이저의 플랫폼 수직 설치각도 $\theta$ 가 매우 작다고 가정하면, 카티너리 라이저는 상부장력 라이저로 근사될 수 있다. 수치해 석의 정확도를 검증하기 위하여 Table 2 와 같은 검증 라이저 모 델에 대하여 수치해석을 수행하고 상용프로그램인 SHEAR7과 비교하였다. 비교 해석을 위하여 검증 모델의 유효장력은 상부 장력으로 가정하였다.

Table 2에서 제시한 검증 모델은 일정한 단면을 가지며, 양단 은 단순지지(Pinned-Pinned)되는 것으로 가정되었다. 또한, 라이 저의 플랫폼 설치점은 해수면과 동일하다고 가정하였다. 라이 저의 길이 $L$ 은 식 (28)에 의해 구할 수 있으며, 고유진동수와 고유모드는 식 (17)과 식 (18)에 의해 구할 수 있다. 라이저 모 델의 고유진동수는 Table 3 에 나타내었으며, 5 차 까지의 고유모 드 $Y(s)$ 와 고유모드의 2 계 미분인 곡률 $Y^{\prime \prime}(s)$ 은 각각 Fig. 4 및 Fig. 5와 같다. 양단이 단순지지되는 조건에서 양단의 $Y(s)$ 와 $Y^{\prime \prime}(s)$ 은 모두 0 이며, 식 (19)에 따라서 와류유기 진동에 의한 응력은 양단에서 작용하지 않는다.

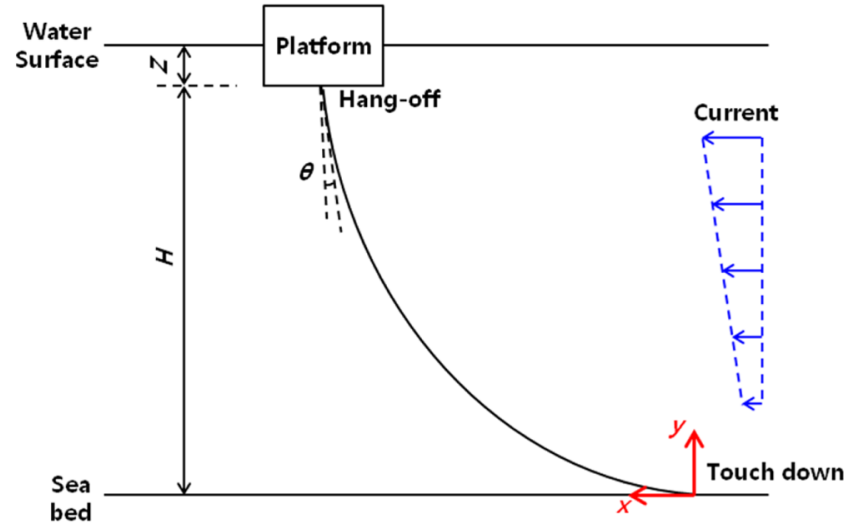

Fig. 3 Steel catenary riser system
Table 2 Verification riser model

\begin{tabular}{ccc}
\hline \hline Item & Value \& Condition & Remarks \\
\hline$H[\mathrm{~m}]$ & 1,000 & \\
$Z[\mathrm{~m}]$ & 0 & Hang-off depth \\
$D[\mathrm{~m}]$ & 0.6 & hydraulic diameter \\
$D_{s}[\mathrm{~m}]$ & 0.6 & steel pipe diameter \\
$m[\mathrm{~kg}]$ & 600 & effective mass \\
$\theta\left[{ }^{\circ}\right]$ & $1 \mathrm{E}-3$ & hang-off angle \\
$E\left[\mathrm{~N} / \mathrm{m}^{2}\right]$ & $2.10 \mathrm{E}+11$ & \\
$T[\mathrm{~N}]$ & (top) $5.02 \mathrm{E}+06$ & linearly varying \\
$S t$ & (bottom) $5.00 \mathrm{E}+06$ & Strouhal number \\
$\rho_{f}[\mathrm{~kg} / \mathrm{m} 3]$ & 0.18 & \\
$\nu\left[\mathrm{m}^{2} / \mathrm{s}\right]$ & 1,025 & fluid viscosity \\
$V[\mathrm{~m} / \mathrm{s}]$ & $1.30 \mathrm{E}-06$ & linearly varying \\
\hline
\end{tabular}

Table 3 Natural frequencies (verification model)

\begin{tabular}{cccc}
\hline \hline \multirow{2}{*}{ Mode No. } & \multicolumn{2}{c}{ Freq. $[\mathrm{Hz}]$} & \\
\cline { 2 - 3 } & Present & SHEAR7 & Difference [\%] \\
\hline 1 & 0.046 & 0.046 & 0.2 \\
2 & 0.092 & 0.092 & 0.2 \\
3 & 0.138 & 0.139 & 0.4 \\
4 & 0.184 & 0.185 & 0.6 \\
5 & 0.230 & 0.232 & 0.9 \\
\hline
\end{tabular}

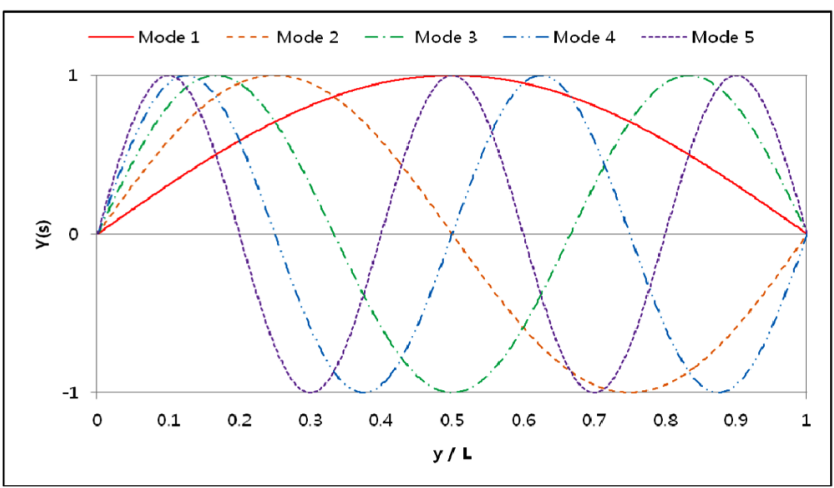

Fig. 4 Mode shapes (verification model)

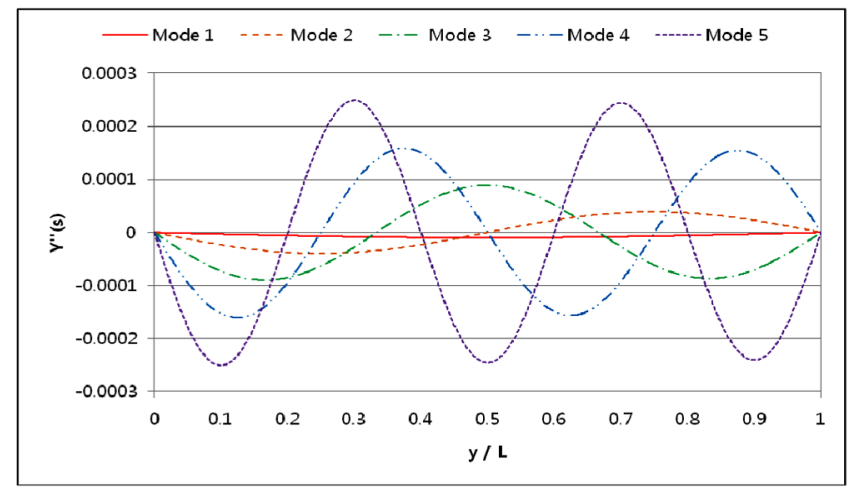

Fig. 5 Curvatures (verification model) 
Table 4 S-N curve properties

\begin{tabular}{c|c|c}
\hline \hline Point & Stress Range $[\mathrm{MPa}]$ & Cycles to Failure \\
\hline 1 & 324.05 & $0.1 \mathrm{E}+05$ \\
\hline 2 & 27.65 & $0.1 \mathrm{E}+09$ \\
\hline
\end{tabular}

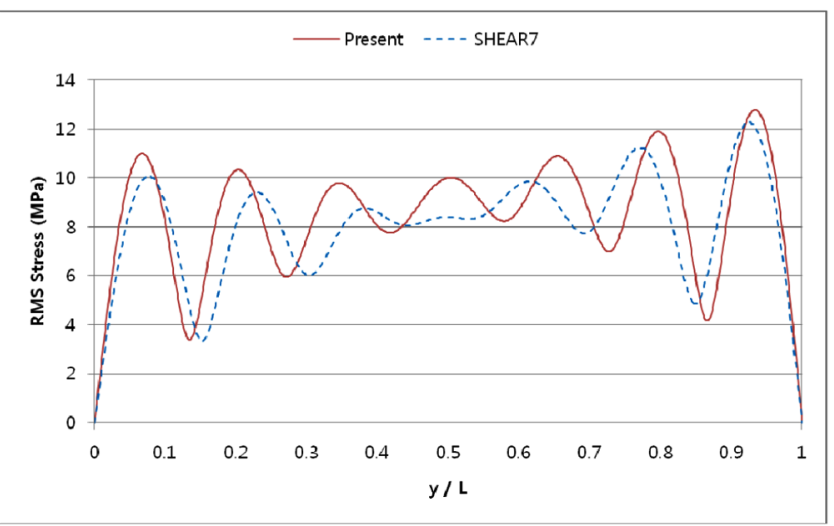

Fig. 6 RMS stress (verification model)

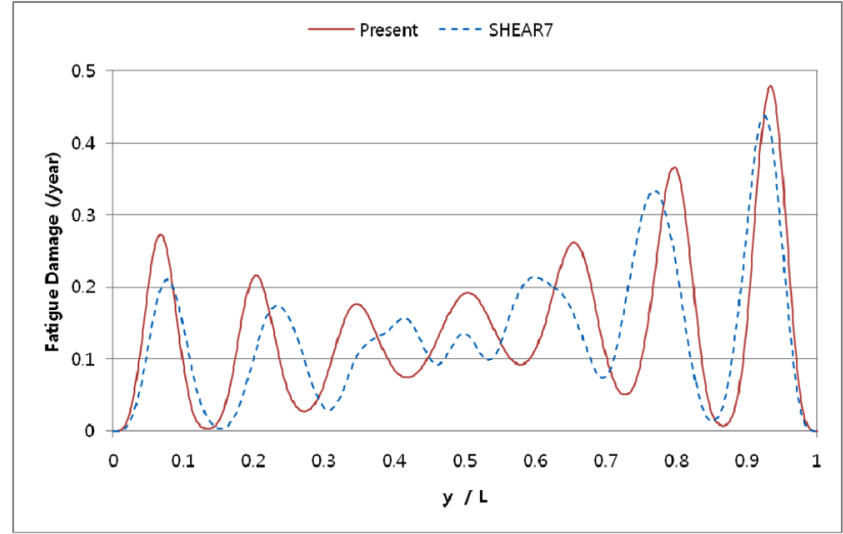

Fig. 7 Fatigue damage (verification model)

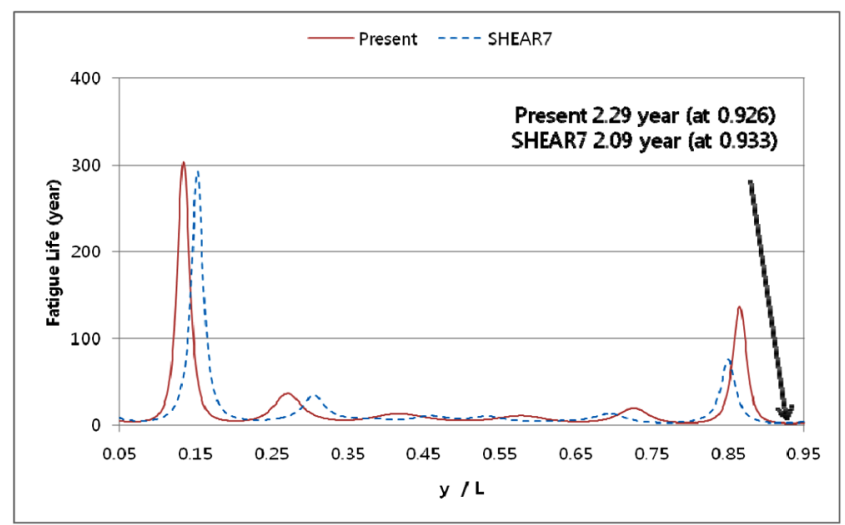

Fig. 8 Fatigue life (verification model)

검증 모델의 와류유기 진동해석에는 모든 가진 모드를 고려 하였으며, 해석 결과는 Fig. 6에 SHEAR7 결과와 함께 나타내었 다. 검증 모델의 최대 응력은 $12.1 \mathrm{MPa}$ 이며, $y / L=0.930$ 에서 발생 하였다. SHEAR7 결과에 따르면, 최대 응력은 $y / L=0.925$ 에서
$12.3 \mathrm{Mpa}$ 이다. 따라서 본 연구의 해석기법이 SHEAR7 결과와 상 당히 부합됨을 확인할 수 있다. 그러나 SHEAR7결과와 일부 차 이를 나타내고 있으며, 이는 모드중첩에 따른 외력의 가진범위 와 기여도의 차이에서 기인하는 것으로 보인다. 피로손상을 계 산하기 위하여 Table 4에 제시된 물성치를 적용하였다(Youn, 2016). 따라서, $N=c S^{-b}$ 로 정의되는 $S-N$ 곡선에서 $b$ 는 3.7421 이며, $c$ 는 7.0406e 35 로 산정된다. 검증 모델의 피로손상 및 피로 수명 해석 결과는 각각 Fig. 7 및 Fig. 8과 같다. 최대 피로 손상 은 라이저 상단에서 발생하였으며, 본 연구에서 피로수명은 2.09년을 나타내었으며 SHEAR7은 2.29년을 나타내었다.

\section{2 수치 모델}

라이저의 플랫폼 수직 설치각도 $\theta$ 가 $12^{\circ}$ 인 카티너리 라이저 모델에 대하여 수치해석을 수행하였다. Table 5에 제시한 수치 모델은 일정한 단면을 가지며, 양단은 검증 모델과 마찬가지로 단순지지(Pinned-Pinned)되는 것으로 가정하였다. 그러나 본 수 치 모델의 유효장력은 카티너리 라이저의 자중과 수직 설치각 도에 의하여 결정된다. 카티너리 라이저의 유효장력은 다음과 같이 나타낼 수 있다.

$$
T(s)=\left\{\left(w s-T_{0, y}\right)^{2}+T_{0, x}^{2}\right\}^{1 / 2}
$$

여기서, $w$ 는 라이저의 단위 길이당 수중 무게, $s$ 는 지반과 접촉 점으로부터 라이저 길이, $T_{0, x}$ 와 $T_{0, y}$ 는 지반과 접촉점에서 유효 장력의 각각 수평 성분과 수직 성분이다.

라이저의 고유진동수는 Table 6에 나타내었으며, 흐름 방향 길이 $X$ 에 대하여 5차 까지의 고유모드와 곡률은 각각 Fig. 9 및 Fig. 10 에 나타내었다. 라이저의 길이 $s / L$ 에 대하여 고유모드와 곡률을 그리면 각각 Fig. 4 및 Fig. 5와 비슷한 그래프를 얻을 수 있다. 양단이 단순지지되는 조건에서 양단의 $Y(s)$ 와 $Y^{\prime \prime}(s)$ 은 모두 0 이며, 식 (19)에 따라서 와류유기 진동에 의한 응력은 양단에서 작용하지 않는다.

Table 5 Catenary riser model

\begin{tabular}{ccc}
\hline \hline Item & Value \& Condition & Remark \\
\hline$H[\mathrm{~m}]$ & 1,356 & \\
$Z[\mathrm{~m}]$ & 144 & Hang-off depth \\
$D[\mathrm{~m}]$ & 0.3556 & hydraulic diameter \\
$D_{s}[\mathrm{~m}]$ & 0.3556 & steel pipe diameter \\
$m[\mathrm{~kg}]$ & 328.3 & effective mass \\
$m[\mathrm{~kg}]$ & 124.7 & submersible mass \\
$\theta\left[{ }^{\circ}\right]$ & 12 & hang-off angle \\
$E\left[\mathrm{~N} / \mathrm{m}^{2}\right]$ & $2.07 \mathrm{E}+11$ & \\
$S t$ & 0.18 & Strouhal number \\
$\rho_{f}[\mathrm{~kg} / \mathrm{m} 3]$ & 1,025 & \\
$\nu\left[\mathrm{m}^{2} / \mathrm{s}\right]$ & $1.30 \mathrm{E}-06$ & fluid viscosity \\
$V[\mathrm{~m} / \mathrm{s}]$ & (top) 1.0 & linearly varying \\
\hline
\end{tabular}


Table 6 Natural frequencies (catenary model)

\begin{tabular}{cc}
\hline \hline Mode No. & Freq. [Hz] \\
\hline 1 & 0.102 \\
2 & 0.203 \\
3 & 0.305 \\
4 & 0.407 \\
5 & 0.509 \\
\hline
\end{tabular}

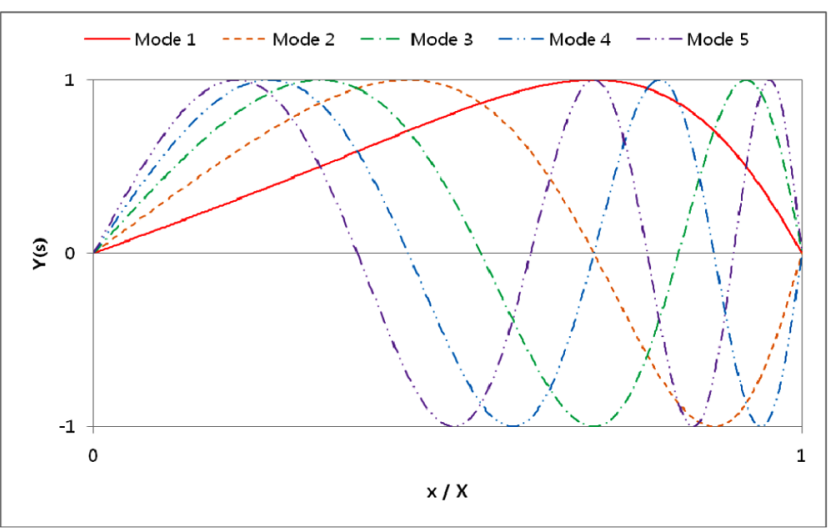

Fig. 9 Mode shapes (catenary model)

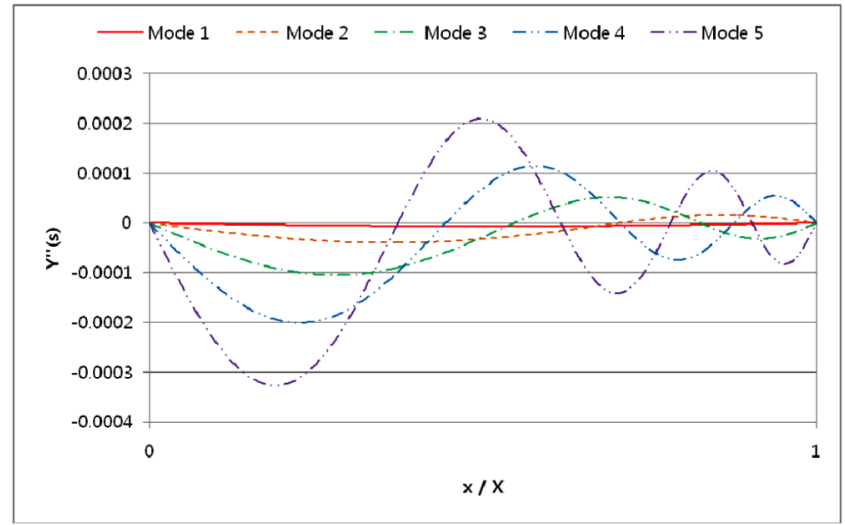

Fig. 10 Curvatures (catenary model)

카티너리 라이저 모델의 와류유기 진동해석에는 모든 가진 모드를 고려하였으며, 와류유기 진동해석 결과는 Fig. 11에 나 타내었다. 검증 모델의 최대 응력은 $15.6 \mathrm{MPa}$ 이며, $x / X=0.035$ 에 서 발생하였다. 와류유기 진동에 의한 피로손상을 계산을 위하 여 Table 4에 제시된 물성치를 적용하였다. 검증 모델의 피로손 상 및 피로수명 해석 결과는 각각 Fig. 12 및 Fig. 13과 같다. 최 대 피로 손상은 유효장력이 상대적으로 작은 라이저 하단에서 발생하였으며, 피로수명은 0.18 년을 나타내었다.

라이저의 플랫폼 수직 설치각도 $\theta$ 가 다른 5 가지 카티너리 라 이저 모델에 대하여 와류유기 진동 응답을 관찰하였다. 라이저 의 기본 물성치는 Table 5의 카티너리 라이저와 동일하며, 수직 설치각도는 $12^{\circ}$ 를 기준으로 증감된다. 해석 모델은 마찬가지로 일정한 단면을 가지며 양단은 단순지지(Pinned-Pinned)되는 것으 로 가정하였다. 5 가지 카티너리 라이저 모델의 고유진동수 및 라이저의 전체 길이는 Table 7에 나타내었다. 또한, 수직 설치각

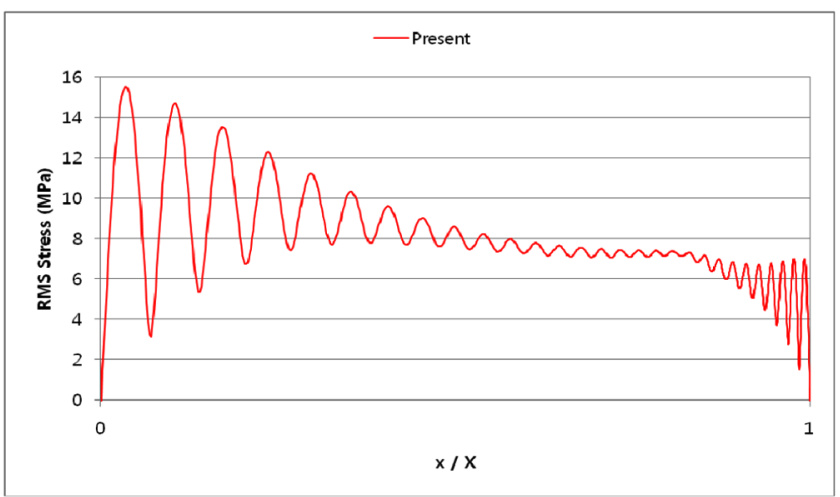

Fig. 11 RMS stress (catenary model)

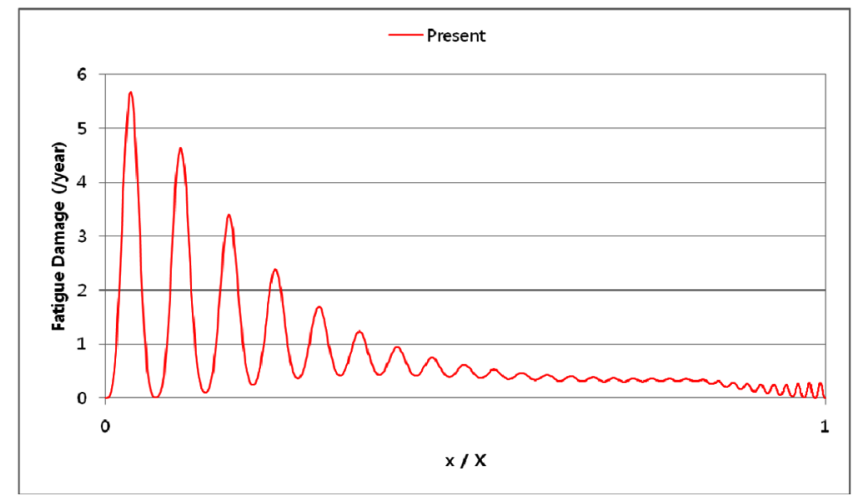

Fig. 12 Fatigue damage (catenary model)

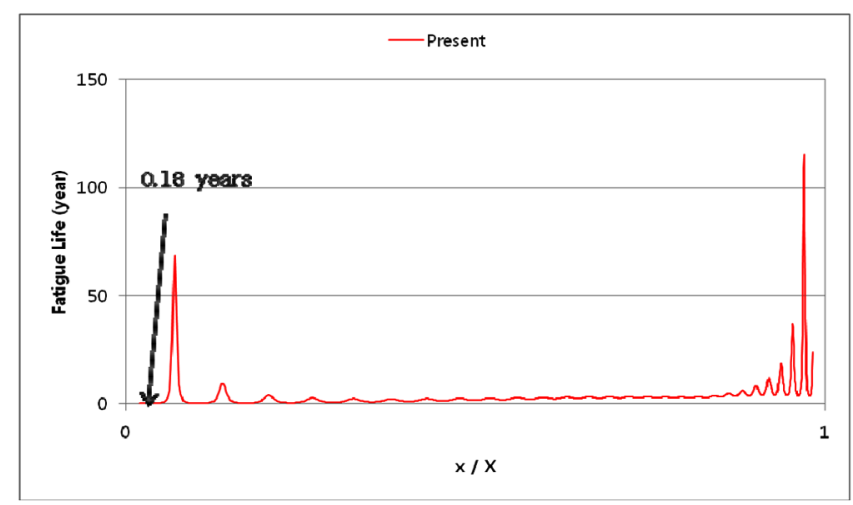

Fig. 13 Fatigue life (catenary model)

도에 따른 최대 RMS 응력은 Table 8 에 나타내었으며, 흐름 방 향 길이 $X$ 에 대하여 RMS 응력은 Fig. 14에 나타내었다.

Table 7 Natural frequencies and lengths (various models)

\begin{tabular}{ccccccc}
\hline \hline \multicolumn{2}{c}{$\theta\left[^{\circ}\right]$} & 10 & 11 & 12 & 13 & 14 \\
\hline & Mode 1 & 0.100 & 0.101 & 0.102 & 0.102 & 0.103 \\
Freq. & Mode 2 & 0.201 & 0.202 & 0.203 & 0.205 & 0.206 \\
{$[\mathrm{~Hz}]$} & Mode 3 & 0.301 & 0.303 & 0.305 & 0.307 & 0.309 \\
& Mode 4 & 0.401 & 0.404 & 0.407 & 0.410 & 0.412 \\
& Mode 5 & 0.502 & 0.505 & 0.509 & 0.512 & 0.515 \\
\hline \multicolumn{2}{c}{$\mathrm{L}[\mathrm{m}]$} & 1,616 & 1,645 & 1,675 & 1,705 & 1,736 \\
\hline
\end{tabular}


Table 8 Maximum RMS stresses (various models)

\begin{tabular}{cccccc}
\hline \hline$\theta\left[{ }^{\circ}\right]$ & 10 & 11 & 12 & 13 & 14 \\
\hline Max. RMS stress [MPa] & 19.4 & 17.3 & 15.6 & 14.2 & 13.1 \\
\hline
\end{tabular}

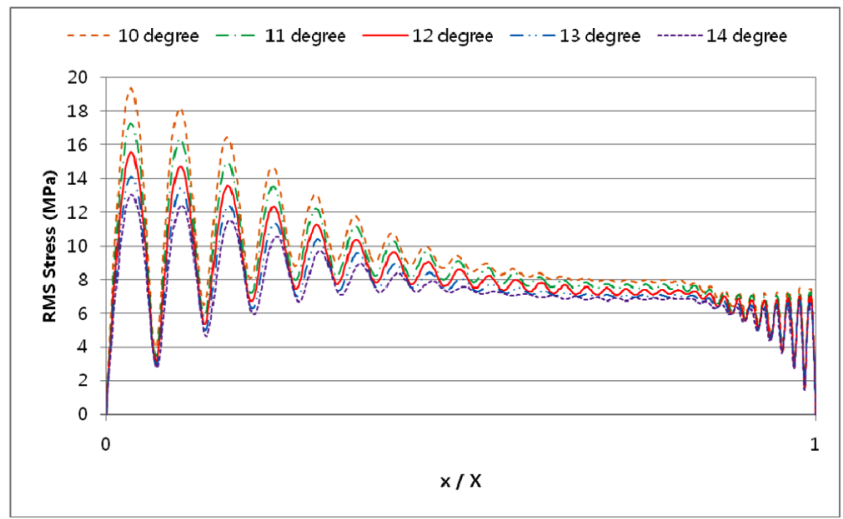

Fig. 14 RMS stresses (various models)

수직 설치각도 $\theta$ 가 증가함에 따라서 라이저의 길이도 증가하 였지만, 고유진동수는 거의 변화가 없었다. 이는 수직 설치각도 $\theta$ 가 증가한 라이저의 유효장력이 증가하여 오히려 고유진동수 를 증가시켰기 때문이다. 따라서 해당 범위 내에서는 수직 설치 각도 $\theta$ 가 증가함에 따라서 와류유기 진동에 의한 RMS 응력은 감소하는 것으로 나타났다.

\section{4. 결 론}

본 연구에서는 모드중첩법에 기반한 수치모델을 이용하여 카 티너리 라이저의 와류유기 진동 수치해석기법을 정립하였다. 길이가 지름에 비하여 매우 큰 심해 라이저를 유연한 케이블로 근사하였으며, 와류흘림에 대한 라이저의 동적 응답을 관찰하 였다. 카티너리 라이저에 대한 해석을 검증하기 위하여 라이저 의 수직 설치각도를 0 으로 가정하여 상부장력 라이저로 이상화 하였으며, SHEAR7 결과와 비교하여 그 타당성을 검토하였다. SHEAR7과 일부 차이는 모드중첩에 따른 외력의 가진범위와 기 여도의 차이에서 기인하는 것으로 보인다.

정립된 해석 기법을 이용하여 카티너리 라이저의 와류유기 피로손상과 피로수명을 계산하였으며, 수직 설치각도의 변화에 따른 사례 연구를 통하여 카티너리 라이저의 응답 특성을 관찰 하였다. 수직 설치각도가 증가함에 따라서 라이저의 길이도 증 가하였지만, 고유진동수는 거의 변화가 없었다. 이는 수직 설치
각도가 증가한 라이저의 유효장력이 증가하여 오히려 고유진동 수를 증가시켰기 때문이며, 일정한 수직 설치각도 범위에서는 각도가 증가함에 따라서 와류유기 진동에 의한 RMS 응력은 감 소하는 것으로 나타났다.

라이저의 와류유기 진동에 대한 정도를 향상하기 위하여 다 양한 해석 및 실험 결과와 비교 등을 통한 외력에 대한 추가적 인 연구가 필요하다.

\section{References}

Det Norske Veritas (DNV), 2006. Recommended Practice DNVRP-F105, Free Spanning Pipelines, Det Norske Veritas.

Gao, Y., Zong, Z., Sun, L., 2011. Numerical Prediction of Fatigue Damage in Steel Catenary Riser due to Vortex-Induced Vibration. Journal of Hydrodynamics, 23(2), 154-163.

Gopalkrishnan, R., 1993. Vortex-Induced Forces on Oscillating Bluff Cylinders, Sc. D. Thesis. Massachusetts Institute of Technology and Woods Hole Oceabigraphic Institute.

Kim, K.H., 2013. Dynamic Response Analysis of Top-Tensioned Riser under Sheared Cureent Load. Journal of Ocean Engineering and Technology, 27(4), 83-89.

Park, S.J., Kwon, H.J., Lee, I., Han, J.H., 2004. Flow-Induced Vibration Analysis of Bridge Girder Section. Journal of Korean Society for Noise and Vibration Engineering, 14(5), 402-409.

Vandiver, J.K., Li, L., 2005. SHEAR7 V4.4 Program Theoretical Manual. Massachusetts Institute of Technology.

Vandiver, J.K., Li, L., 2015. User Guide for SHEAR7 Version 4.9a. Massachusetts Institute of Technology.

Venugopal, M., 1996. Damping and Response Prediction of a Flexible Cylinder in a Current, Ph.D. Thesis. Massachusetts Institute of Technology.

Vikestad, K., 1998. Multi-Frequency Response of a Cylinder Subjected to Vortex Shedding and Support Motions, Ph.D. Thesis, Norwegian University of Science and Technology.

Vikestad, K., Larsen, C.M., Vandiver, J.K., 2000. Damping of Vortex-Induced Vibrations. Offshore Technology Conference, Paper No. OTC 11998, Houston, Texas.

Youn, J.Y., 2016. Dynamic Response and Fatigue Life Estimation of Top-Tensioned Marine Riser according to the Methods to Determine Power-in Region and Distribution, Master Thesis. Pusan National University. 